\title{
Folhas de girassol mexicano como alternativa no manejo de Pratylenchus brachyurus em quiabeiro
}

\author{
Francisco de Alcântara Neto ${ }^{1}$, Keyla Cosme Delpupo ${ }^{1}$, Gilson Soares da Silva ${ }^{2}$, Geraldo de Amaral Gravina ${ }^{3}$, \\ Maruzanete Pereira de Melo ${ }^{4}$, José Evando Aguiar Beserra Júnior ${ }^{1}$
}

${ }^{1}$ Programa de Pós-Graduação em Agronomia/Agricultura Tropical, Universidade Federal do Piauí, CEP: 64049-550, Teresina - PI. ${ }^{2}$ Universidade Estadual do Maranhão, caixa postal 09, CEP: 65055-970, São Luís - MA. ${ }^{3}$ Universidade Estadual do Norte Fluminense Darcy Ribeiro, CEP: 28013-602, Campos dos Goytacazes - RJ. ${ }^{4}$ Universidade Federal do Oeste do Pará, CEP: 68170-000, Juruti - PA.

Autor para correspondencia: Francisco de Alcântara Neto (fneto@ufpi.edu.br)

Data de chegada: 18/09/2016. Aceito para publicação em: 29/12/2017.

$10.1590 / 0100-5405 / 169428$

\section{RESUMO}

Alcântara Neto, F.; Delpupo, K.C.; Silva, G.S.; Gravina, G.A.; Melo, M.P.; Beserra Júnior, J.E.A. Folhas de girassol mexicano como alternativa no manejo de Pratylenchus brachyurus em quiabeiro. Summa Phytopathologica, v.44, n.3, p.267-270, 2018.

Objetivou-se verificar o potencial de folhas de girassol mexicano (Tithonia diversifolia) como alternativa de manejo ao nematoide Pratylenchus brachyurus em quiabeiro. Foram conduzidos dois ensaios em casa de vegetação, em delineamento inteiramente casualizado, com sete repetições, sendo cada parcela composta por um vaso contendo uma planta. Utilizou-se o quiabeiro como planta indicadora e o sorgo como testemunha suscetível. Os tratamentos foram cinco níveis de fitomassa verde e seca $\left(0,5,10,15\right.$ e $20 \mathrm{~g} \mathrm{~kg}^{-1}$ de solo) de $T$. diversifolia, incorporada ou na forma de cobertura do solo, para avaliar o efeito sobre a população de P. brachyurus. A incorporação de folhas frescas de T. diversifolia no solo, como adubo verde, reduziu a população de $P$. brachyurus 60 dias após a inoculação, com destaque para o nível de $20 \mathrm{~g} \mathrm{~kg}^{-1}$ de solo que possibilitou reduzir a população do nematoide ( $\mathrm{FR}=0,00)$. Com $5 \mathrm{~g}$ de fitomassa seca, em cobertura, de T. diversifolia foi possível reduzir 2,96 \% a população do nematoide, enquanto que os níveis de fitomassa seca de 10,15 e $20 \mathrm{~g} \mathrm{~kg}^{-1} \mathrm{de}$ solo eliminou o patógeno. Conclui-se que a incorporação ao solo de folhas frescas de $T$. diversifolia, e a cobertura morta com folhas de T. diversifolia sobre o solo, na forma de fitomassa seca, proporcionaram redução na população de $P$. brachyurus no solo e nas raízes de quiabeiro, sendo uma alternativa importante para o manejo de P. brachyurus

Palavras-chave: nematoide das lesões radiculares, plantas antagonistas, Tithonia diversifolia.

\section{ABSTRACT}

Alcântara Neto, F.; Delpupo, K.C.; Silva, G.S.; Gravina, G.A.; Melo, M.P.; Beserra Júnior, J.E.A. Mexican sunflower leaves as an alternative for the management of Pratylenchus brachyurus in okra. Summa Phytopathologica, v.44, n.3, p.267-270, 2018.

The objective of this study was to verify the potential of Mexican sunflower leaves (Tithonia diversifolia) as an alternative for the management of the nematode Pratylenchus brachyurus in okra. Two trials were conducted in a greenhouse, in a completely randomized design, with seven replicates, and each plot consisting of one pot containing one plant. Okra was used as an indicator plant and sorghum as a susceptible control. Treatments were five levels of green and dry phytomass $\left(0,5,10,15\right.$ and $20 \mathrm{~g} \mathrm{~kg}^{-1}$ soil $)$ of $T$. diversifolia, incorporated in the soil or as soil cover, to evaluate their effect on P. brachyurus population. The incorporation of fresh leaves of $T$. diversifolia in the soil as green manure reduced $P$. brachyurus population 60 days after inoculation, especially the level of $20 \mathrm{~g} \mathrm{~kg}^{-1}$ soil, which allowed complete reduction in the nematode population $(\mathrm{FR}=0.00)$. At $5 \mathrm{~g}$ dry phytomass of $T$. diversifolia, as soil cover, nematode population could be reduced by $2.96 \%$, while the dry phytomass levels of 10 , 15 and $20 \mathrm{~g} \mathrm{~kg}^{-1}$ soil eliminated the pathogen. In conclusion, the incorporation of fresh leaves of $T$. diversifolia in the soil and mulching with $T$. diversifolia leaves on the soil, in the form of dry phytomass, provided a reduction in the population of $P$. brachyurus in the soil and in the roots of okra, constituting an important alternative for the management of $P$. brachyurus.

Keywords: root lesion nematode, plant antagonist, Tithonia diversifolia.

O nematoide das lesões radiculares, Pratylenchus brachyurus (Godfrey) é um dos fitonematoides mais importantes para a agricultura, causando danos e perdas em diferentes culturas, notadamente em soja, milho, algodão e feijão (4).

Entre os métodos utilizados no manejo dos nematoides, o uso de nematicidas no tratamento de sementes e o emprego de variedades resistentes são os mais recomendados, no entanto este último, embora muito eficiente, não está disponível para muitas culturas $(1,22)$.

Outra alternativa consiste na utilização de plantas antagonistas, que possuem na parte aérea compostos nematicidas pré-formados que podem contribuir na redução da população de nematoide quando depositadas sobre o solo ou incorporadas (4). Os compostos provenientes da decomposição dessas plantas atuam no ciclo biológico dos fitonematoides através da ação dos extratos ou subprodutos, como também podendo liberar exsudados radiculares tóxicos que impedem diretamente o processo de infecção e reprodução do nematoide nas raízes $(5,12,24,25)$.

Dentre as diversas famílias botânicas que possuem efetividade no manejo de nematoides, as asteráceas possuem potencial promissor, pois produzem diversos aleloquímicos (27). Tithonia diversifolia é conhecida popularmente como girassol mexicano e mais de 150 compostos já foram isolados dela, como lactonas sesquiterpênicas, 
tirotundina, tagitinina $\mathrm{A}$, tagitinina $\mathrm{C}$, flavonóides, taninos, fenóis $(8,10,13,21,22,23)$. Além destes, outros compostos com atividade fitoterápica e alelopática, efeito nematicida, entre outros, já foram identificados (16). Outros estudos utilizando plantas antagonistas, com foco no manejo de nematoides, já foram realizados $(5,6,19,20)$, entretanto trabalhos direcionados com esta espécie para manejo de $P$. brachyurus em quiabeiro são incipientes.

Devido à ausência de pesquisas sobre esta espécie vegetal no manejo de $P$. brachyurus, este trabalho teve como objetivo avaliar o potencial de folhas de girassol mexicano ( $T$. diversifolia) como alternativa no manejo de P. brachyurus em cultivo de quiabeiro.

\section{MATERIAL E MÉTODOS}

Foram conduzidos dois ensaios no Departamento de Fitotecnia da Universidade Federal do Piauí - UFPI, em Teresina-PI. A população original de P. brachyurus foi obtida a partir de plantas de soja (Glycine $\max (\mathrm{L}$.) Merrill) procedentes do município de Bom Jesus - PI, sendo identificação da espécie realizada no Laboratório de Nematologia do Campus Professora Cinobelina Elvas/UFPI, em Bom Jesus - PI, mediante observações microscópicas de espécimens de Pratylenchus, confrontando-as com aquelas descritas na literatura para a espécie $P$. brachyurus.

Inicialmente, em casa de vegetação sem controle de umidade e temperatura do ambiente, foram produzidas mudas de quiabeiro $\mathrm{cv}$. Santa Cruz 47, sendo a semeadura realizada em bandejas de polietileno com 50 células, contendo como solo previamente autoclavado (120 ${ }^{\circ} \mathrm{C}$ por $1 \mathrm{~h}$ ) e esterco bovino, na proporção 2:1. Quinze dias após a emergência foi realizado o transplantio das mudas de quiabeiro para vasos de polietileno com capacidade de $2,8 \mathrm{~kg}$, contendo $2 \mathrm{~kg}$ de solo autoclavado $\left(120^{\circ} \mathrm{C}\right.$ por $\left.1 \mathrm{~h}\right)$. As plantas foram irrigadas manualmente, duas vezes ao dia, até a avaliação do experimento.

O primeiro ensaio foi implantado para avaliar o efeito da incorporação ao solo de folhas frescas de T. diversifolia no manejo de $P$. brachyurus. Algumas plantas de T. diversifolia foram cultivadas em canteiros e, após 90 dias (mês de agosto/2014), coletadas folhas frescas às 15 horas da tarde, as quais foram cortadas em pedaços de aproximadamente $1 \mathrm{~cm}^{2}$, com auxílio de tesoura, e pesadas para obtenção dos níveis de fitomassa fresca.

Os tratamentos consistiram de cinco níveis de fitomassa fresca $(0$, 5, 10, 15 e $20 \mathrm{~g} \mathrm{~kg}^{-1}$ de solo) de T. diversifolia incorporada no solo, com sete repetições, utilizando-se uma planta por parcela, sendo cada parcela representada por um vaso. A viabilidade do inóculo foi confirmada utilizando-se o sorgo como testemunha suscetível.

Mudas de quiabeiro com 15 dias de idade, produzidas em bandejas de polietilenos, foram transplantadas para vasos onde haviam sido incorporadas as diferentes dosagens de folhas de $T$. diversifolia ao solo. Logo após, a suspensão de nematoides foi distribuída em orifícios feitos próximo ao coleto das plantas, infestando-se o solo com $10 \mathrm{~mL}$ da suspensão, contendo 24 nematoides $/ \mathrm{mL}$. A concentração do inóculo foi estimada com o auxílio de uma lâmina de Peters. O inóculo foi multiplicado em sorgo (Sorghum bicolor), em vasos contendo solo previamente autoclavado, sob condições de casa de vegetação, durante 90 dias.

Sessenta dias após a infestação do solo com os nematoides, as plantas foram retiradas dos vasos e coletados $100 \mathrm{~cm}^{3}$ de solo de cada vaso. Em laboratório, o sistema radicular de cada planta foi lavado em água corrente, seco em folhas de papel toalha e separado da parte aérea. Foi determinado o número de nematoides existentes no solo e nas raízes (nematoides $\mathrm{g}^{-1}$ ), em cada parcela, pelos métodos de Coolen \& D'Herde (3) e Jenkins (7).

A população final $\left(\mathrm{P}_{\mathrm{f}}\right)$ foi estimada pela contagem em lâmina de Peters, utilizando microscópio óptico. Após a contagem, foram calculados os fatores de reprodução $\left(\mathrm{FR}=\mathrm{P}_{\mathrm{f}} / \mathrm{P}_{\mathrm{i}}\right)$, utilizando-se a metodologia descrita por Oostenbrink (18).

No segundo ensaio, visando avaliar o efeito da cobertura do solo com folhas secas de $T$. diversifolia sobre $P$. brachyurus, folhas verdes de girassol mexicano foram coletadas e colocadas em sacos de papel e, posteriormente, submetidas à desidratação em estufa de secagem e esterilização com circulação de ar forçada, regulada para $60{ }^{\circ} \mathrm{C}$ pelo período de 72 horas. Retirada toda a umidade, as folhas secas foram trituradas em liquidificador.

Os tratamentos foram constituídos pelos níveis de fitomassa seca $\left(0,5,10,15\right.$ e $20 \mathrm{~g} \mathrm{~kg}^{-1}$ de solo) de T. diversifolia cobrindo o solo, com sete repetições. Quinze dias após a emergência, plântulas de quiabeiro foram transplantadas para vasos contendo folhas secas de $T$. diversifolia depositadas 7 dias antes sobre o solo, o qual foi mantido úmido para facilitar a decomposição das folhas. Realizou-se a inoculação das plantas com distribuição da suspensão de inóculo (10 $\left.\mathrm{mL} \mathrm{planta}^{-1}\right)$, na concentração de 50 exemplares de $P$. brachyurus $\mathrm{mL}^{-1}$, na superfície do solo e recobrindo-o totalmente. As avaliações foram feitas conforme descrito no experimento anterior.

Para análise dos dados, antes de serem submetidos à análise de variância (ANOVA), foram avaliadas as pressuposições de normalidade e de homogeneidade de variâncias pelos testes de Lilliefors (9) e Bartlett (2), respectivamente. Uma vez não atendidos tais requisitos, utilizou-se a transformação por $\sqrt{ }(x+0,5)$ e, após a transformação foi verificada novamente pelos testes apropriados $(2,9)$, atendendo às pressuposições de normalidade e homogeneidade de variâncias dos erros. Então, os dados foram submetidos à ANOVA. Após a análise de variância, no caso de significância para os tratamentos, foram ajustados modelos de regressão linear e não-linear para explicar a relação funcional entre os níveis de fitomassa de $T$. diversifolia e o número de nematoides no solo e na raiz. Entretanto, não houve nenhum ajuste significativo de nenhum dos modelos de regressão testados, baseando-se na ANOVA da regressão, nos coeficientes de determinação e na significância dos coeficientes das equações de regressão. A partir destes resultados, apesar de se tratar de tratamentos quantitativos, optou-se por realizar o teste de comparações de médias (Tukey), pois era notável a diferença entre as médias das testemunhas e os demais tratamentos que continham algum nível de fitomassa de $T$. diversifolia.

Para ambos os testes foi utilizado o nível de $5 \%$ de probabilidade, com o auxílio do aplicativo computacional ASSISTAT ${ }^{\circledR}$. As transformações só foram utilizadas para efeitos de análises de variâncias, porém os dados apresentados e discutidos foram os dados originais.

\section{RESULTADOS E DISCUSSÃO}

Os dados quantitativos não apresentaram efeito de regressão nos diversos modelos avaliados (linear, quadrático, exponencial, logarítmica), impossibilitando explicar a relação funcional entre a variável independente (níveis de folhas de $T$. diversifolia) e as variáveis dependentes (número de nematoides por $100 \mathrm{~mL}$ de solo e na raiz). Desta forma, o uso do teste de médias foi utilizado para analisar os dados obtidos. 
A viabilidade do inoculo foi confirmada pelo maior nível populacional de $P$. brachyurus na testemunha suscetível (plantas de sorgo), tanto no solo quanto na raiz, apresentando $\mathrm{FR}=1,35$ (Tabela 1). Este resultado é corroborado por aqueles relatados por Neves (14), que ao avaliar a reprodução de $P$. brachyurus em diferentes gramíneas forrageiras, verificou maior nível populacional de $P$. brachyurus em plantas de sorgo $(\mathrm{FR}=1,57)$, confirmando o grau de suscetibilidade desta gramínea a este nematoide.

A suscetibilidade do quiabeiro a $P$. brachyurus foi estudada anteriormente por Machado et al. (11) que, ao avaliarem 18 espécies olerícolas em casa de vegetação, verificaram que o quiabeiro cv. Santa Cruz foi um dos melhores hospedeiros de P. brachyurus, aumentando a população em 15 vezes, 65 dias após a inoculação.

Houve redução na população de $P$. brachyurus no solo e nas raízes das plantas nos diferentes níveis de fitomassa utilizados (T2, T3, T4 e T5) em comparação à testemunha (T1) em que não se incorporou folhas frescas de T. diversifolia (Tabela 1). Como P. brachyurus é endoparasito migrador, a incorporação das folhas reduziu a população do nematoide no solo e, consequentemente, a penetração nos tecidos das raízes.

Observou-se diferença significativa entre o FR do quiabeiro quando se comparou os tratamentos com incorporação de folhas de $T$. diversifolia no solo com o tratamento 1 , sem a incorporação de folhas. A utilização dos níveis 5, 10, 15 e $20 \mathrm{~g} \mathrm{~kg}^{-1}$ de solo, de folhas de $T$. diversifolia incorporadas ao solo, reduziu a população do nematoide em 92, 97, 90 e $100 \%$, respectivamente, em relação à testemunha (Tabela 1).

Em um estudo para avaliar o potencial nematicida de algumas plantas antagonistas, das quais a $T$. diversifolia fazia parte, Osei et al. (20) verificaram que a incorporação ao solo, em condições naturais de campo, dos restos culturais de girassol mexicano possibilitou a redução da densidade populacional de Meloidogyne e Pratylenchus em 86 e $87 \%$, respectivamente, em comparação à testemunha (tomateiro). Os resultados encontrados no presente estudo, o qual tem como foco apenas as folhas de $T$. diversifolia sobre $P$. brachyurus, são corroborados por aqueles encontrados por Osei et al (20) e reforça o potencial do girassol mexicano no manejo desse nematoide.

A redução populacional de $P$. brachyurus nesse experimento pode estar relacionada à decomposição das folhas de $T$. diversifolia que liberou substância nematicida e, consequentemente, causando toxicidade aos nematoides. Tal fato pode ser sustentado pelos resultados encontrados por Slomp et al. (26), que verificaram que flavanóides provenientes de extratos de folhas de $T$. diversifolia apresentaram ação nematicida em $P$. zeaee $P$. jaehni. Estes autores relatam que os flavonóides são sintetizados pelas plantas em resposta às infecções microbianas, justificando sua ação antimicrobiana frente a vários microrganismos. O potencial nematicida dessa planta pode ser atribuído à presença de terpenos nos tecidos da planta (23).

A utilização de diferentes níveis de fitomassa de T. diversifolia sobre o solo reduziu a população de P. brachyurus (Tabela 2). Os tratamentos 3, 4 e 5, nos níveis de 10, 15 e 20 g respectivamente, apresentaram redução de até $100 \%$ do número de nematoides no solo e na raiz das plantas de quiabeiros, com $F R=0,0$. Este fato reforça a atividade nematicida de $T$. Diversifolia que durante o processo de decomposição libera possíveis aleloquímicos, contribuindo diretamente no manejo deste fitonematoide.

Plantas pertencentes à família Asteraceae, produzem compostos secundários como glicocosídeos de triterpenos e apresentam significativas propriedades nematicidas, agindo diretamente na

Tabela 1. $\mathrm{N}^{\mathrm{o}}$ de nematoides/100 $\mathrm{mL}$ de solo e $\mathrm{N}^{\mathrm{o}}$ de Nematoide/grama de raiz de quiabeiro (Abelmoschus esculentus) aos 60 dias após a infestação do solo com Pratylenchus brachyurus e incorporação de folha fresca de girassol mexicano (T. diversifolia) ao solo em diferentes concentrações (tratamentos). Teresina-PI, UFPI, 2014

\begin{tabular}{|c|c|c|c|}
\hline Tratamentos $(\mathrm{T})$ & $\mathrm{N}^{0}$ de nematoides/ $100 \mathrm{~mL}$ de solo & $\mathbf{N}^{0}$ de Nematoide/ grama de raiz & F R \\
\hline $\mathrm{T} 1-(0 \mathrm{~g})$ & $91,40 \mathrm{a}$ & $131,40 \mathrm{~b}$ & $0,99 \mathrm{a}$ \\
\hline $\mathrm{T} 2-(5 \mathrm{~g})$ & $10,00 \mathrm{~b}$ & $15,70 \quad \mathrm{c}$ & $0,10 \mathrm{~b}$ \\
\hline $\mathrm{T} 3-(10 \mathrm{~g})$ & $0,00 \mathrm{~b}$ & $11,40 \quad \mathrm{c}$ & $0,04 \mathrm{~b}$ \\
\hline $\mathrm{T} 4-(15 \mathrm{~g})$ & $8,50 \mathrm{~b}$ & $22,80 \quad \mathrm{c}$ & $0,13 \mathrm{~b}$ \\
\hline $\mathrm{T} 5-(20 \mathrm{~g})$ & $0,00 \mathrm{~b}$ & $0,00 \quad \mathrm{c}$ & $0,00 \mathrm{~b}$ \\
\hline Testemunha suscetível (sorgo) & $105,70 \mathrm{a}$ & $220,00 \mathrm{a}$ & $1,35 \mathrm{a}$ \\
\hline CV (\%) & $37,60 \%$ & $40,50 \%$ & $9,40 \%$ \\
\hline
\end{tabular}

Médias seguidas de mesma letra, na coluna, não diferem estatisticamente, $(\mathrm{p} \leq 0,05)$ pelo teste de Tukey. FR - Fator de reprodução. CV - Coeficiente de variação.

Tabela 2. $\mathrm{N}^{\circ}$ de nematoides $/ 100 \mathrm{~mL}$ de solo e $\mathrm{N}^{\circ}$ de Nematoide/grama de raiz de quiabeiro (Abelmoschus esculentus) aos 60 dias após a infestação do solo com Pratylenchus brachyurus e efeito da cobertura morta de folhas de girassol mexicano (T. diversifolia) em diferentes concentrações (tratamentos). Teresina-PI, UFPI, 2014

\begin{tabular}{|c|c|c|c|}
\hline Tratamentos $(\mathrm{T})$ & $\mathrm{N}^{0}$ de nematoides/ $100 \mathrm{~mL}$ de solo & $\mathrm{N}^{0}$ de Nematoide/ grama de raiz & FR \\
\hline $\mathrm{T} 1-(0 \mathrm{~g})$ & $165,70 \mathrm{a}$ & $508,50 \mathrm{a}$ & $1,35 \mathrm{~b}$ \\
\hline $\mathrm{T} 2-(5 \mathrm{~g})$ & $5,71 \mathrm{~b}$ & $17,10 \mathrm{~b}$ & $0,04 \mathrm{c}$ \\
\hline $\mathrm{T} 3-(10 \mathrm{~g})$ & $0,00 \mathrm{~b}$ & $0,00 \mathrm{~b}$ & $0,00 \mathrm{c}$ \\
\hline $\mathrm{T} 4-(15 \mathrm{~g})$ & $0,00 \mathrm{~b}$ & $0,00 \mathrm{~b}$ & $0,00 \mathrm{c}$ \\
\hline $\mathrm{T} 5-(20 \mathrm{~g})$ & $0,00 \mathrm{~b}$ & $0,00 \mathrm{~b}$ & $0,00 \mathrm{c}$ \\
\hline Testemunha suscetível (sorgo) & $197,10 \mathrm{a}$ & $632,40 \mathrm{a}$ & $1,65 \mathrm{a}$ \\
\hline CV $(\%)$ & $22,90 \%$ & $25,00 \%$ & $7,01 \%$ \\
\hline
\end{tabular}

Médias seguidas de mesma letra, na coluna, não diferem estatisticamente, $(\mathrm{p} \leq 0,05)$ pelo teste de Tukey. FR - Fator de reprodução. CV - Coeficiente de variação. 
membrana plasmática nas larvas de nematoides (15). O efeito do extrato de $T$. diversifolia sobre a eclosão de juvenis de segundo estágio de $M$. incognita, após 15 dias de imersão, reduziu 92,48 \% na eclosão deste fitopatógeno (6). Nos extratos de T. diversifolia, Odeyemi \& Adewale (16) encontraram alcalóides e saponinas que inibiram $98 \%$ a eclosão dos ovos de Meloidogyne incognita, dois dias após a incubação, verificandose inibição de 100 \% na eclosão dos ovos, após nove dias nos testes in vitro. $\mathrm{O}$ uso de plantas que, na sua constituição química, possuem moléculas de ação nematicida é uma excelente opção para utilização no manejo de fitonematoides, pois possuem ação deletéria diretamente no corpo do nematoide, causando imobilidade principalmente na fase J2 e, consequentemente, interferido no processo de penetração (17).

Conclui-se que a incorporação ao solo de folhas frescas de $T$. diversifolia, e a cobertura morta com folhas de $T$. diversifolia sobre o solo na forma de fitomassa seca proporcionaram redução na população de $P$. brachyurus no solo e nas raízes de quiabeiro, sendo uma alternativa importante para o manejo de P. brachyurus.

\section{AGRADECIMENTOS}

Os autores agradecem à Coordenação de Aperfeiçoamento de Pessoal de Nível Superior (CAPES) e à Universidade Federal do Piauí (UFPI).

\section{REFERÊNCIAS}

1. Baldin, E.L.L.; Wilcken, S.R.S.; Pannuti, L.E.R.; Schlick-Souza, E.C.; Vanzei, F.P. Uso de extratos vegetais, manipueira e nematicida no controle do nematoide das galhas em cenoura. Summa Phytopathologica. Botucatu, v.38, n.1, p.36-41, 2012.

2. Bartlett, M. S. Properties of sufficiency and statistical tests. Proceedings of the Royal Society. London, v.160, n.901, p.268-282, 1937.

3. Coolen, W.A.; D'Herde, C.J. A method for the quantitative extraction of nematodes from plant tissue. Ghent: State Nematology and Entomology Station, $1972.77 \mathrm{p}$

4. Corte, G.D.; Pinto, F.F.; Stefanello, M.T.; Gulart, C.; Ramos, J.P.; Balardin, R.S. Tecnologia de aplicação de agrotóxicos no controle de fitonematoides em soja. Ciência Rural, Santa Maria, v.44, n.9, p.1534-1540, 2014.

5. Ferraz, S.; Freitas, L.G.; Lopes, E.A.; Dias-Arieira, C.R. Manejo sustentável de fitonematoides. 1.ed. Viçosa: UFV, 2010.v.1, 245 p.

6. Ferreira, I.C.M.; Silva, G.S.; Nascimento, F.S. Efeito de extratos aquosos de espécies de Asteraceae sobre Meloidogyne incognita. Summa Phytopathologica, Botucatu, v.39, n.1, p.40-44, 2013

7. Jenkins, W.R.A. rapid centrifugal-flotation technique for separation nematodes from soil. Plant Disease Reporter, Beltsville, v. 48, n.41, p.692-695, 1964

8. Lee, M. Y.; Liao, M.H.; Tsai, Y.N.; Chiu, K.H.; Wen, H.C. Identification and anti-human glioblastoma activity of tagitinin $\mathrm{C}$ from Tithonia diversifolia methanolic extract. Journal of Agriculture and Food Chemistry, Washington, v. 59, n. 6, p. $2347-2355,2011$
9. Lilliefors, H.W. On the Kolmogorov Smirnov test for normality with mean and variance unknown. Journal of the American Statistical Association, Alexandria, v.62, n.318, p.399-402, 1967.

10. Lin, H.R. Sesquiterpene lactones form Tithonia diversifolia act as peroxisome proliferator-activated receptor agonists. Bioorganic \& Medicinal Chemistry Letters, Tokyo, v.22, n.8, p.2954-2958, 2012.

11. Machado, A.C.Z.; Inomoto, M.M. Host status of eighteen vegetable crops for Pratylenchus brachyurus. Nematropica, Hope, v.31, n.2, p. 257- 263, 2001

12. Martins, M. C. B.; Santos, C. D. G. Ação de extratos de plantas medicinais sobre juvenis de Meloidogyne incognita raça 2. Revista Ciência Agronômica, Fortaleza, v.47, n.1, p. 135-142, 2016

13. Miranda, M.A.F.M.; Varela, R.M.; Torres, A.; Molinillo, J.M.G.; Gualtieri, S.C.J.; Macias, F.A. Phytotoxins from Tithonia diversifolia. Journal of Natural Products, Columbus, v.78, n.5, p.1083-1092, 2015.

14. Neves, D.L. Reprodução de Pratylenchus brachyurus em diferentes gramíneas forrageiras. Global Science and Technology, Rio Verde, v.6, p.134-140, 2013.

15. Ntalli, N.G.; Caboni, P. Botanical Nematicides: A Review. Journal of Agricultural and Food Chemistry, Washington, v.60, n.40, p.9929-9940, 2012

16. Odeyemi, I.S.; Adewale, K.A. Phythonematoxic properties and nematicidal potential of Tithonia diversifolia extract and residue on Meloidogyne incognita infecting yam (Discoriaro tundata). Archives Phytopathology and Plant Protection. Berlim, v.44, n.18, p.1745 -1753, 2011.

17. Oka, Y. Mechanisms of nematode suppression by organic soil amendments - a review. Applied Soil Ecology, Firenzi, v.44, n.2, p.101-115, 2010.

18. Oostenbrink, M. Major characteristic of relation between nematodes and plants. Medelelingen Landbouw Hogeschool, Wageningen, v.66, p.1-46, 1966.

19. Osei, K.; Fening, J.O.; Gowen, S.R.; Jama, A. The potential of four nontraditional legumes in suppressing the population of nematodes in two Ghanaian soils. Journal of Science and Environmental Management Port Harcourt, v.1, n.4, p.63-68, 2010.

20. Osei, K.; Moss, R.; Nafeo, A.; Addico, R.; Agyemang, A.; Danso, Y.; Asante, J.S. Management of plant parasitic nematodes with antagonistic plants in the forest-savanna transitional zone of Ghana. Journal of Applied Biosciences, Nairobi, v.37, p.2491-2495, 2011.

21. Otusanya, O.; Ilori, O. Phytochemical Screening and the Phytotoxic Effects of Aqueous Extracts of Tithonia diversifolia (Hemsl) A. Gray. International Journal of Biology, Toronto, v.4, n.3, p.97-101, 2012.

22. Pereira, P.S.; Diones, A.D.; Walter, V.; Nasi, A.M.T.T.; Herz, W. Sesquiterpene-lactones from Brazilian Thitonia diversifolia. Phytochemistry, Oklahoma, v.45, n.7, p.1445-1448, 1997.

23. Ragasa, C.Y.; Tempora, M.; Rideout, J.A. Terpenoids from Tithonia diversifolia. Journal of Research in Science, Computing and Engineering, Manila, v.4, n.1, p.1-7, 2007

24. Rodrigues, D.B.; Dias-Arieira, C.R.; Vedoveto, M.V.V.; Roldi, M.; Molin, H.F.D.; Abe, V.H.F. Crop rotation for Pratylenchus brachyurus control in soybean. Nematropica, Hope, v. 44, n.2, p.146-151, 2014.

25. Silva, G. S. Métodos alternativos de controle de fitonematoides. Revisão Anual de Patologia de Plantas, Passo Fundo, v.9, p.81-152, 2011.

26. Slomp, L.; Pereira, P.S.; França, S.C.; Zingaretti, S.; Beleboni, R.O. In vitro nematocidal effects of medicinal plants from São Paulo state, Brasil. Pharmaceutical Biology, London, v.47, n.3, p.230-235, 2009.

27. Tsay, T.T. Evaluation of Asteraceae Plants for Control of Meloidogyne incognita. Journal of Nematology, Hanover, v.36, n.1, p.36-41, 2004. 